\title{
HUMANITY'S BIG QUESTIONS
}

\author{
Translated from Spanish by Aimee Werth
}

\section{Why do cartoon characters always wear the same clothes?}

The answer is found in Quora written by Valerie Fletcher, an animation director who has contributed to shows like South Park, Family Guy and American Dad. Firstly, in many cases, different clothes would result in difficulty identifying the characters, as in South Park, where they all have almost the same face. Secondly, because each change of clothes has to be designed and approved, it is not worth doing if it does not help the plot.

\section{Why does no one say goodbye when they hang up the phone in movies and TV shows?}

Because it is a waste of time. Take for example an episode of The Good Wife where the characters can answer their cellphones every five minutes. Is it really necessary for us to hear "OK, bye for now, talk to you soon" at the end of each of these conversations? No. It can be realistic, but in general, it is boring and unnecessary. Moreover, the screenwriters can take advantage of these extra seconds to add additional elements to the storyline. In this Reddit thread and this one from Quora, the issue is discussed and more details provided.

\section{Why do we turn down the radio when we are looking for a place to park?}

We can give limited attention, "a zero-sum game", as explained in Sharpbrains. To devote more attention to an activity (like looking for parking) we have to take attention away from another activity (like listening to the radio). In contrast, before looking for parking, it is very likely that because we take the same route to the office every day, we are paying attention to the music instead of the road. Another example, taken from Thinking, Fast and Slow: we can easily walk 
and talk at the same time, but if we walk and try to solve a complicated math problem, we are going to walk slower. In other words, we are not multitaskers.

\section{Why can't you tickle yourself?}

When we move our limbs, "the cerebellum produces precise predictions of the movements of our body," as a result, we are incapable of surprising and tickling ourselves: we know where and how we are going to touch ourselves, as explained on the $B B C$.

\section{Each generation is taller, but is there a limit? Are we going to end up being $\mathbf{2 0}$ foot tall monsters? Please, let the answer to this question be yes.}

We have grown about 4 inches in the last 100 years and according to Martin Gent in 70 Curious Questions about the World around Us and Their Surprising Answers, this is thanks above all to "a healthy diet and better health care." But, according to him, this growth is near its end: "Each person's genes set a limit on their maximum height increase. In ideal living conditions this genetic margin can be wholly utilized, but not surpassed." The human body has its limits: excessive height can create cardiovascular and joint problems.

\section{Can you perspire in water?}

As explained in Muy Interesante, when we exercise, the temperature of our bodies begins to climb and the sweat glands are activated. As a result, if the water is cold, we will perspire less. 